\title{
PENGARUH KEPEMIMPINAN DAN MENTORING TERHADAP MOTIVASI DALAM MELAYANI
}

\author{
Ahmad Tabrani \\ STAK Terpadu PESAT \\ ahmadstakpesat@gmail.com
}

\begin{abstract}
Abstraksi
Tujuan dari penelitian ini adalah untuk mendapatkan deskripsi tentang persepsi pengaruh kepemimpinan dan mentoring yang diterima oleh para pemimpin tingkat menengah Yayasan Pelayanan Desa Terpadu terhadap motivasi mereka dalam melakukan tugas pelayanan. Penelitian ini menggunakan metode survei dengan memberikan angket instrumen kepada pemimpin tingkat menengah Yayasan Pelayanan Desa Terpadu yang tersebar di berbagai daerah di Indonesia dengan sampel 60 orang yang ditentukan secara acak. Hasil penelitian menunjukkan bahwa sebagian besar para pemimpin tingkat menengah Yayasan Pelayanan Desa Terpadu memiliki persepsi dalam kategori sangat baik dan baik terhadap pengaruh kepemimpinan dan mentoring yang mereka terima dari para pemimpin dan mentor mereka. Sebagian besar memiliki motivasi sangat baik dan baik dalam melakukan tugastugasnya dan menyatakan bahwa pengaruh kepemimpinan dan mentoring yang mereka terima berpengaruh terhadap motivasi mereka dalam melakukan tugas-tugasnya.
\end{abstract}

Kata Kunci: kepemimpinan, mentoring, motivasi

\begin{abstract}
The purpose of this study is to obtain a description concerning the perception of leadership and mentoring influences received by the middle-level leaders of PESAT in carrying out task ministry. This study uses a survey method by giving questionnaires to middle-level PESAT foundation leaders from various regions in Indonesia with a sample of 60 randomly determined people. The results show that most of the middle-level leaders of PESAT have a perception of the excellent and good category of leadership and mentoring they received from their leaders and mentors. Most of them have very good dan good motivation in carrying out their duties and stated that the influences their motivation in carrying out their duties.
\end{abstract}

Keywords: Leadership, Mentoring, Motivation

\section{A. Pendahuluan}

"Kepemimpinan adalah
mengkomunikasikan kepada
orang lain nilai dan potensi
mereka secara amat jelas
sehingga merekabisa melihat hal
itu dalam diri mereka"l

${ }^{1}$ Stephen R. Covey, The $8^{\text {th }}$ Habit, Melampaui Efektivitas, Menggapai Keagungan, Gramedia Pustaka Utama, Jakarta 2005, hal 145
Tugas pemimpin adalah melakukan perubahan dari suatu kondisi menuju kepada kondisi lain yang lebih baik. Seorang pemimpin harus mampu menolong para pengikutnya membuat dan melihat dengan jelas gambaran masa depan yang mereka akan dicapai baik untuk pribadi 
mereka maupun untuk organisasi. Lima langkah utama yang harus dilakukan adalah mendefinisikan gambaran masa depan, melihat realitas masa kini dengan keberanian menghadapi fakta-fakta brutal, menetapkan langkah dan melakukan langkah-langkah berani untuk bergerak menuju masa depan, dan mengidentifikasi dan menggerakkan berbagai sumber daya internal dan eksternal, serta mengembangkan kapasitas seluruh anggotanya. Dengan demikian pemimpin membawa organisasi dan pengikutnya mengalami pertumbuhan secara terus menerus. Maka diperlukan kemampuan pemimpin untuk mengukur dan mengembangkan sumber daya manusia yang ada dalam lingkup pengaruhnya untuk mencapai sasaran-sasaran yang diinginkan. Mengelola dan mengembangkan sumber daya terutama sumber daya manusia adalah tugas utama bagi seorang pemimpin. Sayangnya hanya sedikit pemimpin yang memiliki kemampuan dan kebiasaan mengelola penyusunan anggaran bagi pengembangan sumber daya manusia dengan benar. ${ }^{2}$

Pemberdayaan akan memberi motivasi dan meningkatkan tanggungjawab dan keterlibatan yang lebih dalam dan lebih luas dari anggota organisasi. Hal ini diungkapkan oleh Derek Rollinson bahwa, iddeally empowerment results in the delegation of power downwards and an expanded level of involvement for employees. $^{2}$ Tugas pemimpinlah untuk terus memotivasi dan menginspirasi semua orang dalam lingkup kepemimpinannya agar melakukan lebih dari yang diharapkan.

\footnotetext{
2 Derek Rolinson, David Edward, and Aysen Broadfield, Oganizational Behavior and Analysis: An Integrated Approach, New York Published 1998, hal 55
}

Proses pemberdayaan dapat dilakukan oleh para pemimpin melalui proses mentoring. Sesuai dengan pendapat Paul D. Stanley dan Robert Clinton yang mendefinisikan mentoring sebagai pengalaman hubungan di mana seseorang memberdayakan orang lain dengan berbagi sumber-sumber atau karunia-karunia yang diberikan Allah. ${ }^{3}$

Yayasan Pelayanan Desa Terpadu (PESAT) sebagai organisasi Kristiani yang telah melayani lebih dari 30 tahun dan menjangkau lebih dari 20 propinsi di Indonesia melalui lebih dari 100 unit pelayanan, sejak awal berdirinya telah menjadikan mentoring sebagai bagian penting dalam proses berorganisasi. Dalam perkembangannya, pada tahun 2017 Yayasan PESAT menjadikan pengembangan kepemimpinan melalui pemuridan (mentoring) seutuhnya sebagai inti gerak organisasi. Hal ini dapat dilihat melalui mission statement Yayasan PESAT untuk "memuridkan anak desa seutuhnya untuk mencapai puncak potensinya". Dan melalui vision statement yayasan PESAT bahwa "pada tahun 2047 PESAT menjadi pelaku utama dalam membangkitkan pemimpin gereja dan masyarakat yang berjuang bagi kepentingan anak miskin pedesaan di bangsa-bangsa".

Salah satu kunci pencapaian visi dan tujuan Yayasan PESAT berada pada tingkat para pemimpin operasional yang memimpin langsung rekan-rekannya dalam implementasi program. Mereka yang masuk dalam kelompok ini adalah para manager area, supervisor dan ketua unit FC pada program divisi. Para waket, mentor dan ketua bidang dalam STAK Terpadu.

\footnotetext{
${ }^{3}$ Togi Simanjuntak, The art Of Mentoring, Jakarta, Metanoia Publishing 2012, hal 27
} 
Para manager ahli dalam divisi litbang dan manager keuangan dan manager sarpras dalam divisi pengelolaan. Mereka adalah orang-orang yang dalam bidangnya masing-masing memiliki anggota yang harus mereka pimpin. Dengan demikian para pemimpin, khususnya pada tingkat manager dan manager operasional seharusnya memiliki pemahaman dan mampu mengimplementasikan kepemimpinan dan mentoring yang memberikan motivasi kuat kepada para anggotanya untuk mendorong mereka melakukan tugas-tugas pelayanannya lebih dari yang diharapkan atau "extra mille". Melalui pemahaman kepemimpinan dan mentoring yang kuat dan implementasi yang benar, maka motivasi para anggota organisasi PESAT akan meningkat. Peningkatan motivasi anggota Yayasan PESAT akan meningkatkan kinerja mereka yang memberi dampak besar bagi pencapaian visi Yayasan PESAT. Namun bagaimana mereka memimpin dan melakukan mentoring kepada anggota timnya juga dipengaruhi oleh kadar kepemimpinan dan mentoring yang mereka terima dari pemimpin dan mentor mereka.

Penelitian ini melakukan survey dengan tujuan:

1. Mendeskripsikan persepsi pengaruh kepemimpinan yang diterima oleh para pemimpin tingkat menengah Yayasan Pelayanan Desa Terpadu.

2. Mendeskripsikan persepsi pengaruh mentoring yang diterima para pemimpin tingkat menengah Yayasan Pelayanan Desa Terpadu.

3. Mendeskripsikan tingkat motivasi dalam mengerjakan tugas-tugas

\footnotetext{
${ }^{4}$ Colquit, LePine \& Wesson, Organizational Behavior, Improving Performance and Commitment in the
}

pelayanan dari para pemimpin tingkat menengah Yayasan Pelayanan Desa Terpadu.

4. Mendeskripsikan persepsi pengaruh kepemimpinan dan mentoring yang diterima para pemimpin tingkat menengah Yayasan Pelayanan Desa Terpadu terhadap motivasi mereka dalam melakukan tugas kepemimpinan mereka.

Dengan asumsi jika tingkat pengaruh kepemimpinan dan mentoring yang diterima oleh para pemimpin level menengah pada Yayasan PESAT berada pada tingkat sangat baik, maka mereka juga akan memiliki motivasi yang tingggi dalam mengerjakan tugas-tugasnya. Dimana hal ini juga akan memberikan pengaruh terhadap kepemimpinan dan mentoring mereka kepada orang-orang yang mereka pimpin.

\section{B. Kepemimpinan, Mentoring Dan Motivasi}

\section{Kepemimpinan}

Colquit dkk menyatakan bahwa, "We define leadership as the use of power and influence to direct the activities of followers toward goal achievement". ${ }^{4}$ Dalam definisi ini, kekuasaan pengaruh, mengarahkan pengikut dan pencapaian tujuan menjadi tekanan yang penting. Kekuasaan dipandang sebagai hal yang penting karena memberikan kemampuan kepada pemimpin untuk memengaruhi orang lain. ${ }^{5}$ Hal senada disampaikan oleh Stephen Robbins dan Timothy Judge mendefenisikan kepemimpinan sebagai kemampuan untuk memengaruhi suatu kelompok menuju pencapaian sebuah visi

Workplace, Fourth Edition, Mc Graw-Hill Education, New York 2015, hal 430

${ }^{5}$ Colquit, opcit, , hal 450 
atau tujuan yang ditetapkan. ${ }^{6}$ Fred Luthans juga berpendapat bahwa,

Besides influence, leadership has been defined in terms of group processes, personality, compliance, particular behavior, persuasion, power, goal achievement, interaction, role differentiation of structure, and combinations of two or more of thesse. ${ }^{7}$

Trianto Safira dalam bukunya mengutip pendapat Joseph C. Rost (1993) yang menyatakan bahwa, kepemimpinan adalah hubungan saling memengaruhi antara pemimpin dan pengikut yang menginginkan perubahan nyata sebagai tujuan bersama. $^{8}$ Bahwa hubungan, perubahan dan tujuan menjadi penting dalam diri seorang pemimpin. Sementara itu John M. Bryson mendefenisikan kepemimpinan sebagai kemampuan menginspirasi dan memobilisasi orangorang untuk melakukan kegiatan kelompok bagi kepentingan bersama, so what is leadership? We define as "the inspiration and mobilization of others to undertake collective action in pursuit of the common good. $^{9}$

Selanjutnya Trianto Safira juga mengutip pendapat James MacGregor Burns yang menyatakan bahwa kepemimpinan atas manusia dilaksanakan dengan memberi motivasi dan tujuan tertentu, menggerakkan sumber daya sehingga membangkitkan keterlibatan para

${ }^{6}$ Stephen P. Robbins \& Timothy A. Judge, Perilaku Organizational, Salemba Empat, Jakarta 2015, hal 249

${ }^{7}$ Luthans, Organizational Behavior, An Evidence-Based Approach. $12^{\text {th }}$ edition, Mc Graw-Hill Irwin, New York 2011, hal 414

8 Trianto Safira. Kepemimpinan. Yogyakarta : Graha Ilmu, 2004.

9 John M. Bryson, Strategic Planning For Public and Nonprofit Organizations, Fourth Edition, Jossey-Bass A Wiley Imprint, San Fransisco 2011, hal 356 pengikutnya. ${ }^{10}$ Maka tugas penting pemimpin adalah memotivasi, membangun tujuan dan menggerakkan sumber daya. Hal senada diungkapkan oleh Stogdill yang dikutip oleh Salusu dimana kepemimpinan didefenisikan sebagai proses memengaruhi kegiatan kelompok dalam perumusan dan pencapaian tujuan. ${ }^{11}$ Namun Salusu juga menekankan pendapat Glenn yang lebih cenderung melihat kepemimpinan dari segi kualitas, yaitu kemampuan atau seni memimpin orang biasa untuk mencapai hasil-hasil yang luar biasa. ${ }^{12}$

George Barna menekankan kepemimpinan kepada panggilan seorang pemimpin, karakter Kristus dalam diri pemimpin dan kemampuan fungsionalnya. Jadi hal terpenting pada pemimpin adalah spiritualitas, karakter dan kompetensi. ${ }^{13}$ Lebih jauh Oswald Sanders menekankan kepemimpinan kepada pengaruhnya kepada orang lain yang bersumber kepada kehidupan rohani dan karakternya. ${ }^{14}$

Namun lebih jauh Robbins dan Timothy menekankan kepada konsep kepemimpinan yang melayani.

Para ahli belakangan ini telah mempertimbangkan

kepemimpinan yang beretika dari suatu sudut yang baru dengan memeriksa kepemimpinan yang melayani. Para pemimpin yang melayani akan melampaui kepentingan diri mereka sendiri dan menitikberatkan pada kesempatan untuk membantu

\footnotetext{
10 Henry dan Richard Blackaby.Kepemimpinan Rohani.Batam:Gospel Press, 2005

11 Prof. Dr. J. Salusu, Pengambilan Keputusan Strategik Untuk Organisasi Publik dan Organisasi Nonprofit, PT

Gramedia Widiasarana Indonesia, Jakarta 1996, hal 192

12 Prof. Dr. Salusu, opcit, hal 193

13 George Barna, Leaders on Leadership (Pemimpin tentang Kepemimpinan.Malang:Gandum Mas,2009. 14 Oswald Sanders, Kepemimpinan Rohani. Yayasan Kalam Hidup
} 
para pengikutnya bertumbuh dan berkembang. ${ }^{15}$

Luthans juga mengemukakan pendapat yang senada dengan menyatakan bahwa tugas penting pemimpin adalah memotivasi, memberi inspirasi dan memberdayakan pengikutnya disamping beberapa tugas lainnya.

One analysis argues that five key leadership roles can help shape managerial successes (and failures) shortly. They include : (1) a strategic vision to motivate and inspire, (2) empowering employees, (3) accumulating and sharing internal knowledge, (4) gathering and integrating external information, and (5) challenging the status quo and enabling creativity. ${ }^{16}$

Bahkan Colquit dkk menekankan bahwa seringkali kepingan yang hilang dalam kepemimpinan adalah kepemimpinan transformatif yang memotivasi dan menginspirasi pengikutnya untuk memiliki komitmen tinggi dan bekerja melampaui harapan dalam mencapai tujuan dimana mereka mampu memberi makna dalam pada setiap tugas yang dilakukan.

The missing piece of this leadership puzzle is what leaders do to motivate their employees to perform beyond expectations.

Transformational leadership involves inspiring followers to commit to a shared vision that

\footnotetext{
15 Stephen P. Robbins \& Timothy A. Judge, opcit, hal 267

16 Luthans, opcit , hal 446

17 Colquit dkk, opcit hal 475-476

18 Ken Blanchard, Apa Itu Kepemimpinan Pelayan? Servant Leadership In Action, BPK Gunung Mulia, Jakarta 2019 hal 10
}

\begin{abstract}
provides meaning to their work while also serving as a role model who helps followers develop their own potential and view problems from a new perspective. ${ }^{17}$
\end{abstract}

Ken Blanchard menekankan tugas visioner pemimpin dalam sebuah organisasi untuk memastikan seluruh anggotanya memiliki visi dan tujuan organisasi, serta memahami tugasnya dan berkontribusi dalam upaya mencapai visi dan tujuan organisasi. ${ }^{18}$ Sedangkan dalam implementasi, pemimpin bertugas memberdayakan setiap anggota organisasinya agar memiliki kompetensi (pengetahuan dan skill) yang memadai untuk melakukan tugas mereka. ${ }^{19}$ Hal senada diungkapkan John C. Maxwell, bahwa ciri dari pemimpin yang berhasil, bahkan syarat utama keberhasilan suatu organisasi adalah meningkatkan kapasitas pengikutnya. $^{20}$

Berdasarkan uraian di atas, dapat disintesiskan bahwa kepemimpinan adalah : kemampuan memengaruhi yang berasal dari karakter Kristus dalam diri pemimpin, kemampuan motivasi orang lain agar terlibat dengan sukarela namun antusias dan kemampuan menggerakkan sumber daya untuk melakukan perubahan demi mencapai tujuan bersama. Dengan indikator: Kemampuan memengaruhi; karakter Kristus, kemampuan memotivasi; keterlibatan pengikut dengan sukarela dan antusias; kemampuan menggerakkan sumberdaya; kemampuan melakukan perubahan; ada tujuan bersama.

\footnotetext{
19 Ken Blanchard, opcit hal 12

20 John Maxwell, The 5 Levels of Leadership, MIC

Publisihing, Surabaya, 2017, hal 238-239
} 


\section{Mentoring}

Menurut Tim Elmore, jantung dari mentoring adalah pemberdayaan, "We refer to this transfer between mentor and mentee as empowerment. This process is the heart of mentoring". ${ }^{21}$

Mentoring secara sederhana adalah proses seseorang membantu orang lain untuk belajar sesuatu dan bila proses tadi tidak terjadi, maka pembelajarannya menjadi kurang baik, lebih lamban, atau bahkan sama sekali tidak akan terjadi (menurut Chip R.Bell, 1996). ${ }^{22}$ Sedangkan menurut MK Feeney, mentoring adalah sebuah proses pengaliran (transmisi) pengetahuan informal, modal sosial dan dukungan psikososial yang dirasakan oleh penerima (orang yang dimentor) yang relevan untuk kerja, karier, atau perkembangan profesional; mentoring memerlukan komunikasi informal, biasanya dengan tatap muka dan berkelanjutan dalam jangka waktu tertentu, antara orang yang dianggap memiliki pengetahuan yang relevan yang lebih besar, bijaksana, atau berpengalaman (mentor) dan orang yang dianggap masih kurang memiliki hal-hal di atas (orang yang dimentor). ${ }^{23}$

Sedangkan menurut Eric Parsloe, Mentoring adalah sebuah proses untuk mendukung dan mendorong orang untuk mengatur cara belajar mereka sendiri agar mereka dapat memaksimalkan potensi mereka, mengembangkan keterampilan, meningkatkan kinerja mereka dan menjadi

\footnotetext{
${ }^{21}$ Tim Elmore, Mentoring, How to Invest Your Life in Others, EQUIP and Emerging Young Leaders, USA 2004, hal 24

22 Togi Simanjuntak, opcit hal. 6

${ }^{23}$ Togi Simanjuntak, opcit hal 6-7

24 Togi Simanjuntak, opcit, hal 7-8
}

orang yang mereka inginkan. ${ }^{24}$ Paul D. Stanley dan Robert Clinton menyatakan bahwa, seorang mentor yang memuridkan akan mengajar dan memberikan kemampuan kepada menteenya perihal dasar-dasar untuk mengikut Kristus. ${ }^{25}$ Lebih jauh Paul D. Stanley dan Robert Clinton berpendapat bahwa "mentoring is a relational experience in which one one person empower another by sharing God given resources." Mentoring ditekankan kepada hubungan dan pemberdayaan orang lain melalui berbagi sumber atau karunia yang diberikan Allah. ${ }^{26}$ Sedangkan John Mallison berpendapat bahwa mentoring adalah hubungan dinamik dari sebuah kepercayaan di mana seseorang memungkinkan orang lain (perempuan atau laki-laki) untuk memaksimalkan anugerah Tuhan dalam kehidupan dan pelayanannya. ${ }^{27}$

Mentoring adalah kemitraan antara mentor (yang memberi bimbingan) dengan mentee (yang menerima bimbingan) yang dirancang untuk membangun kepercayaan diri mentee. ${ }^{28}$ Pendapat lain menyatakan bahwa mentoring adalah hubungan interpersonal dalam bentuk kepedulian dan dukungan antara seseorang yang berpengalaman dan berpengetahuan luas dengan seseorang yang kurang berpengalaman maupun yang pengetahuannya lebih sedikit (Crawford, 2010). ${ }^{29}$ Mentoring juga merupakan hubungan pembelajaran timbal balik dan kolaboratif antara dua orang atau lebih yang memiliki tanggung jawab dan tanggung-

\footnotetext{
25 Paul D. Stanley \& Robert Clinton, Mentor, Anda Perlu Mentor dan Bersedia Menjadi Mentor, Penerbit Gandum Mas, Malang 2004, hal 49.

26 Togi Simanjuntak, opcit hal 27

27 Togi Simanjuntak, opcit hal 28-29

${ }^{28}$ Kaswan. Coaching dan Mentoring, (Bandung,

Alfabeta), hal. 1

${ }^{29}$ Kaswan, opcit hal. 13
} 
gugat/akuntabilitas yang sama untuk membantu mentee bekerja mencapai sasaran pembelajaran yang jelas dan didefinisikan bersama ( Zachary, 2005). ${ }^{30}$

Berdasarkan uraian di atas, maka dapat disimpulkan bahwa mentoring adalah hubungan berdasarkan kepercayaan dalam bentuk kepedulian dan dukungan di mana seseorang memberdayakan orang lain untuk mencapai sasaran pembelajaran yang jelas dan didefinisikan bersama. Dengan indikator hubungan, kepercayaan, kepedulian dan dukungan, pemberdayaan dan sasaran pembelajaran.

Lebih jauh, Kaswan menyatakan bahwa proses mentoring adalah hal penting dalam sebuah organisasi, dimana melalui mentoring akan terjadi proses perbaikan kinerja karyawan, percepatan pembelajaran, pemberdayaan, peningkatan motivasi, dan hal-hal lain yang berdampak kepada efisiensi dan efektifitas organisasi. ${ }^{31}$ Hal senada dikemukakan oleh Dr. Robby I Chandra yang menyatakan hubungan sangat erat antara mentoring dan kepemimpinan, bahwa dalam ilmu kepemimpinan, mentoring terutama dipandang sebagai suatu proses mengembangkan bawahan, pengikut atau orang lain. ${ }^{32}$ Proses mentoring yang dimaksud bukan hanya bagaimana pemimpin menolong bawahannya untuk meningkatkan kompetensi dalam mengerjakan tugas-tugasnya dengan baik, namun juga meliputi proses menularkan kebijaksanaan dan nilai-nilai yang dianut pemimpin melalui teladan hidup dan hubungan yang saling percaya. Dr. John C.

\footnotetext{
30 Kaswan, opcit hal 14

${ }^{31}$ Kaswan, opcit hal $350-360$

32 Dr. Robby I. Chandra, Pemimpin dan Mentoring dalam Organisasi, Generasi Info Media, Jkt 2006, hal 3
}

Maxwell juga menyampaikan mentoring sebagai tugas utama seorang pemimpin, “

"we both believe that mentoring is the first and last task of a leader. It is the first task of a leader because everyone who wants to lead the 'masses' ought to begin by leading one person. It is the last or ultimate task of a leader because the acid test of any leader is - are they able to reproduce themselves in others? Success without a successor is a failure. Both leadership and mentoring are about spiritual multiplication. Both are about developing people. "33

Bahwa kepemimpinan dimulai dengan memimpin satu orang dan pada akhirnya memampukan orang tersebut untuk dapat memimpin orang lain menjadi pemimpin. Carson Pue menegaskan bahwa mentoring adalah proses terbaik bagi para pemimpin senior untuk mengembangkan kepemimpinan para pemimpin muda, terutama dalam membangun karakter mereka. ${ }^{34}$

\section{Motivasi}

Motivasi berasal dari bahasa latin "movere" yang berarti "daya penggerak", tepatnya daya penggerak seseorang dalam berperilaku atau melakukan sesuatu. Daya pengerak tersebut dapat bersumber dari dalam dirinya sendiri maupun dari luar dirinya. Seberapa besar motivasi yang dimiliki seseorang berpengaruh kepada kualitas perilakunya baik dalam kehidupan sehari-hari, dalam bekerja, maupun belajar.

\footnotetext{
33 Tim Elmore, opcit, hal 6

${ }^{34}$ Carson Pue, Mentoring Leaders, Penerbit ANDI,

Yogyakarta, 2010, hal 4
} 
Abraham Maslow mengembangkan teori motivasi bahwa motivasi seseorang dibangun oleh kebutuhannya, dan menyajikan piramida yang dikenal dengan hirarki kebutuhan. Maslow menggambarkan tingkat hirarki kebutuhan manusia yang meliputi kebutuhan: (1) kebutuhan biologis dan fisiologis; (2) kebutuhan keamanan dan keselamatan; (3) kebutuhan social; (4) kebutuhan penghargaan; (5) kebutuhan aktualisasi diri. Hirarki kebutuhan disusun pada order tingkat bawah sampai tingkat atas, berikut hirarki kebutuhan menurut Maslow :

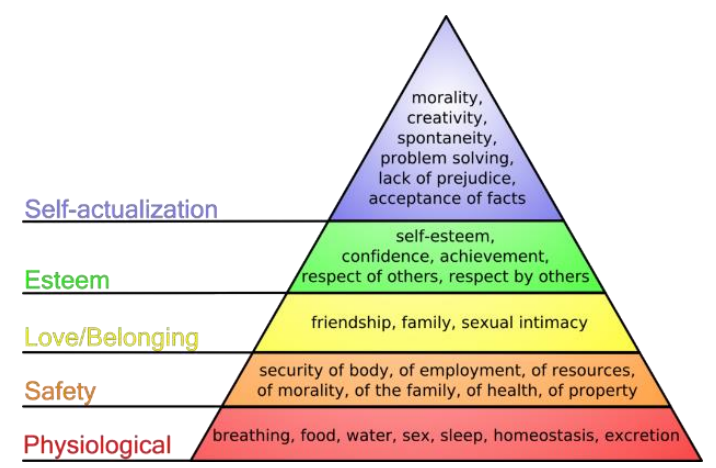

Berdasarkan gambar di atas, terlihat bahwa motivasi tumbuh dalam diri seseorang sesuai pada keberadaan seseorang dalam tingkat hirarki kebutuhan. Semakin tinggi keberadaan seseorang dalam hirarki tersebut, maka semakin tinggi pula motivasinya untuk melakukan hal besar demi terpenuhinya kebutuhan. Sementara Hodgetts mendefenisikan motivasi sebagai :

Motivation is a psychological process through which unsatisfied wants or needs lead to drives that are aimed at goals or incentives. The three basic elements in the process are needs, drives, and goal

35 Richard M. Hodgetts, Fred Luthans, dan Jonathan P. Doh, Internasional Management Culture, Strategy, and Behavior, McGraw Hill New Jersy 2012, hal 422.

${ }^{36}$ Colquitt dkk, Opcit, hal 168 attainment. A person with an unsatisfied need will undertake goal-directed behavior to satisfy the need. ${ }^{35}$

Hodgetts menyoroti tiga elemen dasar yang menjadi sumber motivasi, yaitu kebutuhan, dorongan dan pencapaian tujuan. Seseorang dengan kebutuhan tertentu akan melakukan upaya dan berperilaku yang diarahkan pada tujuan untuk memenuhi kebutuhan.

Colquit, dkk berpendapat bahwa, "motivation is defined as a set of energetic forces that originates both within and outside an employee, initiates work related effort and determine its direction, intensity and persistence". ${ }^{36}$ Motivasi adalah energi yang bersumber dari dalam diri atau luar diri seseorang yang mendorongnya melakukan upaya yang berhubungan dengan pekerjaan yang menentukan arah, intensitas dan ketekunan.

Luthans berpendapat bahwa motivasi adalah proses yang dimulai dengan defisiensi fisiologis atau psikologis atau kebutuhan yang mengaktifkan perilaku yang ditujukan untuk tujuan atau insentif, "motivation is a process that starts with physiological or physiological deficiency or need that activates a behavior or a drive that is aimed at agoal or incentive". ${ }^{37}$ Lebih jauh Ivancevich dan Konopaske menyatakan, "motivation is the set off attitudes predispose a person to act a specific goal directed way". 38 Motivasi adalah serangkaian sikap yang menyebabkan seseorang bertindak untuk mencapai tujuan tertentu. Selanjutnya Robert dan Kinicki mendefinisikan

\footnotetext{
37 Luthans, opcit hal 157

${ }^{38}$ John M. Ivancevich, Robert Konopaske, Human Resource Management, McGraw-Hill New York 2013, hal 54
} 
motivasi sebagai proses psikologi yang berdampak pada peningkatan, tujuan, arah dan kegigihan dalam melakukan sesuatu secara sukarela untuk mencapai tujuan, "motivation represents those psychological processes that cause the arousal, direction and persistence of voluntary action that are goal directed". ${ }^{39}$ Motivasi menurut pendapat Menken adalah :

Motivation is the force that makes us do things. Motivation is present in every lift function. Simple acts such as eating are motivated by hunger. Educational is motivated by the desire for knowledge. Motivators can be anything from reward to coercion. ${ }^{40}$

Motivasi adalah kekuatan melakukan kegiatan, yang hadir dalam setiap fungsi kehidupan dari hal yang sederhana seperti makan karena lapar, pendidikan untuk pengetahuan, hadiah bahkan pemaksaan. Seorang pemimpin perlu mengetahui faktor-faktor yang menjadi sumber motivasi dari orang-orang yang dipimpinnya, karena sumber motivasi berbeda pada setiap orang.

Menurut Robbins. "motivation is the process by which a person's efforts are energized, directed, and sustained toward attaining a goal". ${ }^{41}$ Motivasi adalah proses dimana upaya seseorang diberi energi, terarah, dan berkelanjutan menuju pancapaian tujuan. Schermerhorn mengungkapkan:

Motivation describes forces within the individual that account for the level, direction, and persistence of

39 Robert Kreitner and Angelo Kinicki, Organizational Behavior, Key Concepts, Skills and Best Practices, McGraw-Hill Companies Inc New York 2008, hal 147 40 Ivanka Menken, Organizational Behavior and Leadership Management Essentials, ITIL IT Service Management Framework London 2009 hal 210, 2015 effort expended at work. Simply put, a highly motivated person works hard at a job: an unmotivated person does not. A manager who leads through motivation does so by creating conditions under which other people feel consistently inspired to work hard. ${ }^{42}$

Motivasi menggambarkan kekuatan dalam diri seseorang yang menjelaskan tingkat tanggungjawab, arah, dan kegigihannya mengerjakan sesuatu. Singkatnya kadar kerja keras seseorang ditentukan oleh motivasinya. Manajer yang memimpin melalui motivasi akan menciptakan kondisi agar selalu menginspirasi orang lain untuk bekerja keras. Lebih jauh Clayton Aderfer's berpendapat bahwa, "Existence needs are desires for physiological and material well being, relatedness are desires for satisfying interpersonal relationships, and growth needs are desires for continued personal growth and development". ${ }^{43}$ Tiga kebutuhan manusia adalah kebutuhan akan keberadaan (existence needs), kebutuhan berhubungan (related needs), dan kebutuhan untuk berkembang (growth needs).

Deresky mengemukakan bahwa motivasi memiliki banyak fungsi baik dalam konteks pekerjaan seseorang maupun kehidupan pribadi, dimana konteks tersebut dipengaruhi oleh variabel budaya, yang menentukan sikap dan prilaku seseorang atau kelompok pada tugasnya,

41 Stephen P. Robbins dan Mary Coulte, Management Global Edition, Person Education limited England 2012, hal 480.

42 John R. Schermerhom et. al., Organizational Behavior, John Wiley \& Sons Inc USA 2011, hal 362

43 John R. Schermerhorn, opcit hal 112 
"Motivation is very much a function of the context of a person's work and personal life. That contexts influenced by cultural variables, which affect the attitude and behaviors of individuals (and group) on the job". ${ }^{4}$ Deresky juga berpendapat, "motivation is situational and savvy managers use all they know about the relevant culture or subculture- consulting frequently with local people-to infer the best means of motivating in that context". ${ }^{45}$

Mengingat motivasi bersifat situasional, maka pemimpin yang cerdas akan menggunakan seluruh pengetahuannya tentang budaya atau subbudaya dan meminta pendapat orang untuk mendapakan cara terbaik memotivasi orang-orang yang dipimpinnya secara relevan. Dalam hal ini pengaruh kepemimpinan melalui proses mentoring menjadi faktor penting untuk tumbuhnya motivasi bagi anggota organisasi.

Dari uraian di atas maka dapat disimpulkan bahwa motivasi adalah dorongan atau kemauan yang dimiliki seorang baik yang berasal dari dirinya sendiri maupun dari lingkungan yang menyebabkan seorang melakukan upaya terbaik untuk mencapai yang diinginkannya. Dengan indikator memiliki perencanaan, ada tujuan yang ingin dipenuhi, hasrat kuat menyelesaikan pekerjaan, dan kesediaan untuk bekerja keras.

\section{Metodologi Penelitian}

Penelitian dilakukan dengan menggunakan metode survey, yang dilakukan pada bulan Januari sampai Februari 2020. Survey dilakukan dengan

44 Helen Dresky, International Management Managing Across Brodersand Cultures, Pearson Prentise Hall New Jersey 2008 hal 269. mengajukan instrumen pertanyaan mengenai kepemimpinan, mentoring dan motivasi kepada 60 responden yang dipilih secara acak di antara para manager area, supervisor, ketua unit pelayanan FC, para mentor dan staf lain yang dalam tugas pelayanannya juga memimpin orang lain.

Dalam operasional penelitian ini, kepemimpinan adalah pendapat atau persepsi para pemimpin tingkat menengah Yayasan Pelayanan Desa Terpadu mengenai pengaruh kepemimpinan yang diterima mereka dari para pemimpin mereka, sedangkan mentoring adalah pendapat atau persepsi para pemimpin tingkat menengah Yayasan Pelayanan Desa Terpadu mengenai pengaruh mentoring yang diterima mereka dari para mentor mereka. Motivasi adalah pendapat para pemimpin tingkat menengah Yayasan Pelayanan Desa Terpadu mengenai tingkat motivasi mereka dalam mengerjakan tugastugas pelayanan. Sedangkan pengaruh kepemimpinan dan mentoring terhadap motivasi adalah pendapat atau persepsi para pemimpin tingkat menengah Yayasan Pelayanan Desa Terpadu mengenai pengaruh kepemimpinan dan mentoring yang diterima terhadap motivasi mereka dalam melakukan tugas pelayanan.

Survey dilakukan dengan mengajukan 15 butir instrumen pertanyaan mengenai kepemimpinan, 15 butir instrumen pertanyaan mengenai mentoring, 15 butir pertanyaan mengenai motivasi dan 10 butir pertanyaan mengenai pengaruh kepemimpinan dan mentoring terhadap motivasi. Adapun kisi-kisi instrumen survey adalah :

Tabel 1 : Kisi-kisi instrumen

\footnotetext{
${ }^{45}$ Helen Dresky, opcit hal 279
} 


\begin{tabular}{|l|l|l|l|}
\hline \multirow{2}{*}{ No } & \multicolumn{3}{|c|}{ Variabel } \\
\cline { 2 - 4 } & $\begin{array}{l}\text { Kepemimpina } \\
\mathrm{n}\end{array}$ & $\begin{array}{l}\text { Mentorin } \\
g\end{array}$ & Motivasi \\
\hline 1 & Pengaruh & Hubungan & $\begin{array}{l}\text { Memiliki } \\
\text { perencanaan }\end{array}$ \\
\hline 2 & $\begin{array}{l}\text { Karakter } \\
\text { Kristus }\end{array}$ & $\begin{array}{l}\text { Kepercay } \\
\text { aan }\end{array}$ & $\begin{array}{l}\text { Tujuan yang } \\
\text { ingin dicapai }\end{array}$ \\
\hline 3 & $\begin{array}{l}\text { Memberi } \\
\text { Motivasi }\end{array}$ & $\begin{array}{l}\text { Kepedulia } \\
\text { n dan } \\
\text { dukungan }\end{array}$ & $\begin{array}{l}\text { Hasrat kuat } \\
\text { menyelesaika } \\
\text { nengekerjaan } \\
\text { dengan } \\
\text { sukarela dan } \\
\text { antusias }\end{array}$ \\
\hline 5 & $\begin{array}{l}\text { Kemampuan } \\
\text { menggerakkan } \\
\text { sumberdaya }\end{array}$ & $\begin{array}{l}\text { Pemberda } \\
\text { yaan } \\
\text { pembelaja } \\
\text { ran }\end{array}$ & $\begin{array}{l}\text { Kesediaan } \\
\text { bekerja keras }\end{array}$ \\
\hline 6 & $\begin{array}{l}\text { Melakukan } \\
\text { perubahan }\end{array}$ & & \\
\hline 7 & $\begin{array}{l}\text { Tujuan } \\
\text { bersama }\end{array}$ & & \\
\hline
\end{tabular}

Penilaian pada setiap instrumen pertanyaan survey diberikan dengan menggunakan skala: nilai 9 - 10: sangat baik; nilai 7 - 8: baik; nilai 5 - 6: cukup; nilai 3 - 4: kurang; nilai 1 - 2: sangat kurang. Sedangkan total nilai setiap responden dilakukan dengan menggunakan skala: nilai 128 - 150: sangat baik; nilai 98 - 127: baik; nilai 68 - 97: cukup; nilai 38 67: kurang; nilai 15 - 37: sangat kurang. Namun total nilai setiap responden pada instrumen mengenai pengaruh kepemimpinan dan mentoring terhadap motivasi yang berjumlah 10 butir pertanyaan menggunakan skala: nilai 86 100: sangat baik; nilai 66 - 85: baik; nilai 46 - 65: cukup; nilai 26 - 45: kurang; nilai 10 - 25: sangat kurang.

\section{Hasil Survey}

\section{Hasil Survey Kepemimpinan}

Hasil survey kepemimpinan yang terdiri atas 15 butir instrumen pertanyaan dari 60 responden diperoleh data dengan skor maksimum 150 dan skor minimum 57, dari hasil skor maksimum dan minimum diperoleh rentang skor sebesar 93. Dari hasil perhitungan diperoleh nilai rata-rata (mean) 120,4 sedangkan nilai rata-rata (mean) perbutir pertanyaan adalah 8,027. Diperoleh nilai median (nilai tengah adalah) 122,5 dan nilai modus (nilai yang paling sering muncul adalah 146 dan 150 yang masing-masing muncul sebanyak 4 kali.

Hasil survey menunjukkan bahwa terdapat 25 responden $(41,67 \%)$ mencapai skor nilai 128 - 150, yang berarti memiliki persepsi sangat baik terhadap pengaruh kepemimpinan yang diterima. Terdapat 26 responden $(43,33 \%)$ mendapat skor nilai 98 - 127 atau yang memiliki persepsi baik terhadap pengaruh kepemimpinan yang diterima. Terdapat 8 responden $(13,33 \%)$ mendapat skor nilai $68-97$ atau memiliki persepsi cukup terhadap pengaruh kepemimpinan yang diterima. Dan hanya terdapat 1 responden $(1,67 \%)$ dengan skor nilai 38 - 67 atau memiliki persepsi kurang terhadap pengaruh kepemimpinan yang diterima. Tidak ada responden yang memperoleh skor nilai 15 - 37 atau memiliki persepsi sangat kurang terhadap pengaruh kepemimpinan yang diterima. Berikut gambaran data dalam bentuk diagram :

\section{Hasil Survey Kepemimpinan}

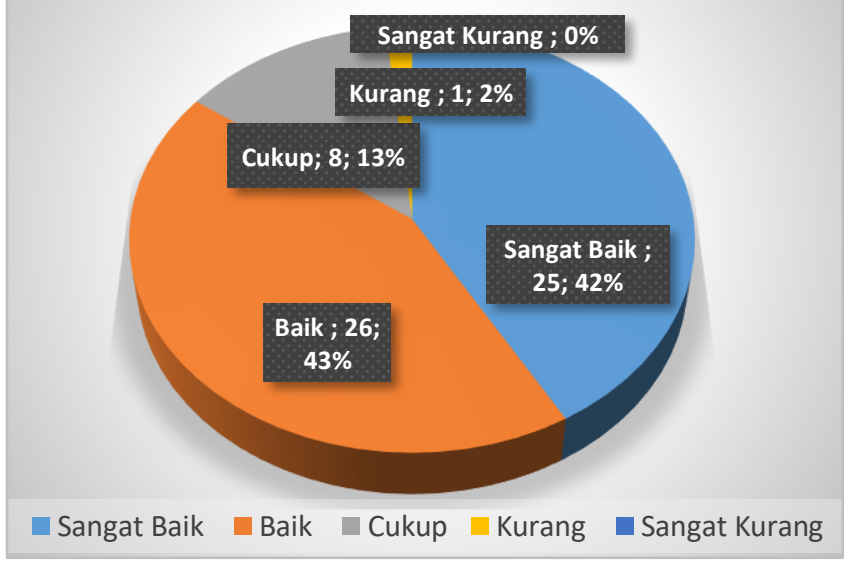




\section{Hasil Survey Mentoring}

Hasil survey mentoring yang terdiri atas 15 butir instrumen pertanyaan dari 60 responden diperoleh data dengan skor maksimum 150 dan skor minimum 72, dari hasil skor maksimum dan minimum diperoleh rentang skor sebesar 78. Dari hasil perhitungan diperoleh nilai rata-rata (mean) 121,833 sedangkan nilai rata-rata (mean) perbutir pertanyaan adalah 8,122 Diperoleh nilai median (nilai tengah) 126 dan nilai modus (nilai yang paling sering muncul) adalah 123, 126, 132, dan 137 yang masing-masing muncul sebanyak 3 kali.

Hasil survey menunjukkan bahwa terdapat 26 responden $(43,33 \%)$ mencapai skor nilai $128-150$, yang berarti memiliki persepsi sangat baik terhadap pengaruh mentoring yang diterima. Terdapat 26 responden $(43,33 \%)$ mendapat skor nilai 98

- 127 atau yang memiliki persepsi baik terhadap pengaruh mentoring yang diterima. Terdapat 8 responden $(13,33 \%)$ mendapat skor nilai 68 - 97 atau memiliki persepsi cukup terhadap pengaruh mentoring yang diterima. Dan tidak terdapat responden dengan skor nilai 38 67 atau memiliki persepsi kurang terhadap pengaruh mentoring yang diterima. Juga tidak terdapat responden yang memperoleh skor nilai $15-37$ atau memiliki persepsi sangat kurang terhadap pengaruh mentoring yang diterima. Berikut adalah gambaran data dalam bentuk diagram :

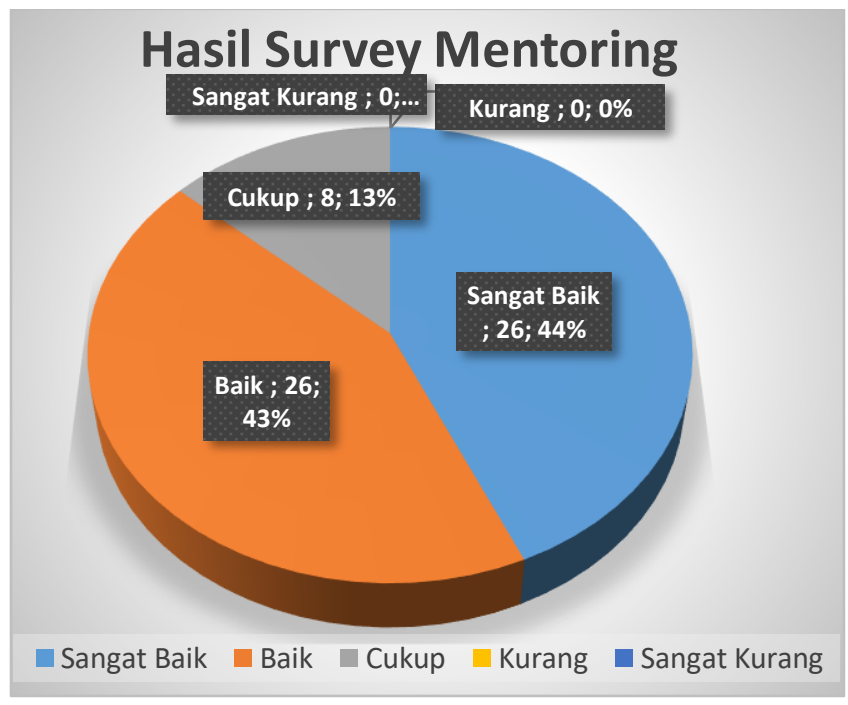

\section{Hasil Survey Motivasi}

Hasil survey motivasi yang terdiri atas 15 butir instrumen pertanyaan dari 60 responden diperoleh data dengan skor maksimum 150 dan skor minimum 81, dari hasil skor maksimum dan minimum diperoleh rentang skor sebesar 69. Dari hasil perhitungan diperoleh data dengan nilai rata-rata (mean) 120,27 sedangkan nilai rata-rata (mean) perbutir pertanyaan adalah 8,08 . Diperoleh nilai median (nilai tengah adalah) 121 dan nilai modus (nilai yang paling sering muncul) adalah 124 yang muncul sebanyak 5 kali.

Hasil survey menunjukkan bahwa terdapat 20 responden $(33,33 \%)$ mencapai skor nilai $128-150$, yang berarti memiliki motivasi sangat baik dalam mengerjakan tugas-tugasnya. Terdapat 35 responden $(58,33 \%)$ mendapat skor nilai $98-127$ atau memiliki motivasi baik dalam mengerjakan tugas-tugasnya. Terdapat 5 responden $(8,33 \%)$ mendapat skor nilai $68-97$ atau memiliki motivasi cukup dalam mengerjakan tugas-tugasnya. Dan tidak terdapat responden dengan skor nilai 38 67 atau memiliki memiliki motivasi kurang dalam mengerjakan tugas-tugasnya. Demikian juga tidak ada responden yang memperoleh skor nilai $15-37$ atau 
memiliki motivasi sangat kurang dalam mengerjakan tugas-tugasnya. Berikut gambaran data dalam bentuk diagram :

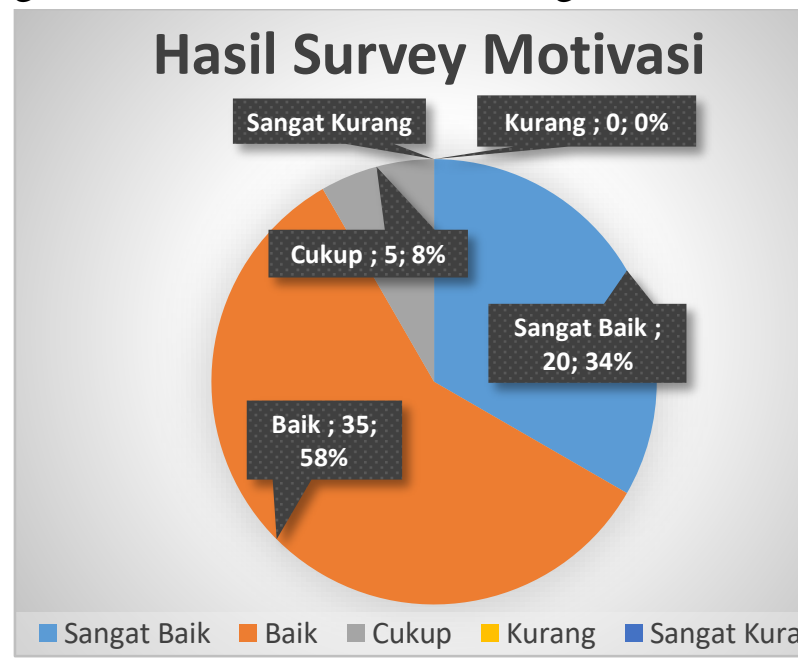

\section{Hasil Survey Pengaruh}

\section{Kepemimpinan \& Mentoring} Terhadap Motivasi

Hasil survey pengaruh

kepemimpinan dan mentoring terhadap motivasi yang terdiri atas 10 butir instrumen pertanyaan dari 60 responden diperoleh data dengan skor maksimum 100 dan skor minimum 49, dari hasil skor maksimum dan minimum diperoleh rentang skor sebesar 51. Dari hasil perhitungan dengan nilai rata-rata (mean) 79,67 sedangkan nilai rata-rata (mean) perbutir pertanyaan adalah 7,967. Diperoleh nilai median (nilai tengah adalah) 80,5 dan nilai modus (nilai yang paling sering muncul) adalah 100 yang muncul sebanyak 6 kali.

Hasil survey menunjukkan bahwa terdapat 22 responden $(36,67 \%)$ mencapai skor nilai 86 - 100, yang berarti memiliki persepsi sangat baik tentang pengaruh kepemimpinan dan mentoring terhadap motivasi mereka dalam melakukan tugastugasnya. Terdapat 29 responden $(48,33 \%)$ mendapat skor nilai 66 - 85 atau memiliki memiliki persepsi baik tentang pengaruh kepemimpinan dan mentoring terhadap motivasi mereka dalam melakukan tugastugasnya. Terdapat 9 responden (15\%) mendapat skor nilai $46-65$ atau memiliki memiliki persepsi cukup tentang pengaruh kepemimpinan dan mentoring terhadap motivasi mereka dalam melakukan tugastugasnya. Dan tidak terdapat responden dengan skor nilai 26 - 45 atau memiliki memiliki persepsi kurang tentang pengaruh kepemimpinan dan mentoring terhadap motivasi mereka dalam melakukan tugastugasnya. Demikian juga tidak ada responden yang memperoleh skor nilai 10 - 25 atau memiliki memiliki persepsi sangat kurang tentang pengaruh kepemimpinan dan mentoring terhadap motivasi mereka dalam melakukan tugastugasnya. Berikut gambaran data dalam bentuk diagram :

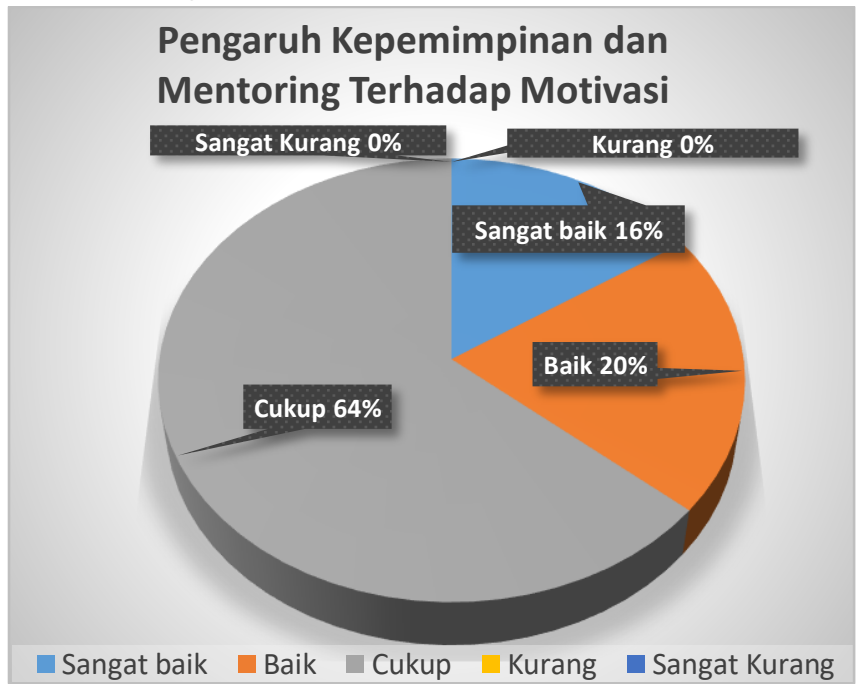

Secara umum dalam bentuk tabel, kita melihat hasil data survey sebagai berikut :

Tabel 2 : Hasil Survey

\begin{tabular}{|c|c|c|c|c|c|c|}
\hline \multirow{2}{*}{$\begin{array}{l}\mathrm{N} \\
\mathrm{O}\end{array}$} & \multirow{2}{*}{$\begin{array}{l}\text { Instrumen } \\
\text { survey }\end{array}$} & \multicolumn{5}{|c|}{ Data hasil survey } \\
\hline & & $\begin{array}{c}\text { Sangat } \\
\text { baik }\end{array}$ & Baik & Cukup & Kurang & $\begin{array}{l}\text { Sangat } \\
\text { kurang }\end{array}$ \\
\hline 1 & $\begin{array}{l}\text { Persepsi } \\
\text { Pengaruh } \\
\text { kepemimpin } \\
\text { an }\end{array}$ & $\begin{array}{c}25 \\
(41,7 \%)\end{array}$ & $\begin{array}{c}26 \\
(43,3 \\
\%)\end{array}$ & $\begin{array}{c}8 \\
(13,3 \%)\end{array}$ & $\begin{array}{c}1 \\
(1.7 \%)\end{array}$ & $\begin{array}{c}0 \\
(0 \%)\end{array}$ \\
\hline 2 & $\begin{array}{l}\text { Persepsi } \\
\text { pengaruh } \\
\text { mentoring }\end{array}$ & $\begin{array}{c}26 \\
(43,3 \%)\end{array}$ & $\begin{array}{c}26 \\
(43,3 \\
\%)\end{array}$ & $\begin{array}{c}8 \\
(13,3 \%)\end{array}$ & $\begin{array}{c}0 \\
(0 \%)\end{array}$ & $\begin{array}{c}0 \\
(0 \%)\end{array}$ \\
\hline 3 & $\begin{array}{l}\text { Tingkat } \\
\text { motivasi } \\
\text { yang } \\
\text { dimiliki }\end{array}$ & $\begin{array}{c}20 \\
(33,3 \%)\end{array}$ & $\begin{array}{c}35 \\
(58,3 \\
3 \%)\end{array}$ & $\begin{array}{c}5 \\
(8.3 \%)\end{array}$ & $\begin{array}{c}0 \\
(0 \%)\end{array}$ & $\begin{array}{c}0 \\
(0 \%)\end{array}$ \\
\hline
\end{tabular}




\begin{tabular}{|l|l|c|c|c|c|c|}
\hline 4 & $\begin{array}{l}\text { Persepsi } \\
\text { pengaruh } \\
\text { kepemimpin } \\
\text { an dan } \\
\text { mentoring } \\
\text { terhadap } \\
\text { motivasi }\end{array}$ & $(36,7 \%)$ & $\begin{array}{c}29 \\
(48,3\end{array}$ & $\begin{array}{c}9 \\
(15 \%)\end{array}$ & $\begin{array}{c}0 \\
(0 \%)\end{array}$ & $(0 \%)$ \\
& & & & & \\
\hline
\end{tabular}

Terpadu memiliki persepsi pengaruh kepemimpinan dan mentoring dalam kategori baik dan sangat baik terhadap tingkat motivasi mereka dalam

Melalui tabel hasil survey di atas, kita dapat melihat bahwa pengaruh kepemimpinan, pengaruh mentoring, tingkat motivasi dan pengaruh kepemimpinan dan mentoring terhadap motivasi berada dalam kategori sangat baik dan kategori baik pada sebagian besar responden. Namun kategori sangat baik yang dicapai pada variabel kepemimpinan sebesar $41,67 \%$ dan variabel mentoring dalam kategori baik sebesar 43,33\%, tidak diikuti oleh variabel motivasi dalam kategori sangat baik yang mencapai angka $33,33 \%$. Dalam kategori sangat baik, masih terdapat kesenjangan antara pengaruh kepemimpinan dan pengaruh mentoring terhadap tingkat motivasi mereka.

\section{E. Kesimpulan}

Berdasarkan data hasil survey, maka dapat disimpulkan bahwa : (1) Sebagian besar atau sebanyak $85 \%$ para pemimpin tingkat menengah pada Yayasan Pelayanan Desa Terpadu memiliki persepsi pengaruh kepemimpinan yang diterima dalam kategori baik dan sangat baik; (2) Sebagian besar atau sebanyak $86,67 \%$ para pemimpin tingkat menengah pada Yayasan Pelayanan Desa Terpadu memiliki persepsi pengaruh mentoring yang diterima dalam kategori baik dan sangat baik; (3) Sebagian besar atau sebanyak $91,67 \%$ para pemimpin tingkat menengah pada Yayasan Pelayanan Desa Terpadu memiliki tingkat motivasi baik dan sangat baik dalam mengerjakan tugas-tugasnya; (4) Sebagian besar atau sebanyak $85 \%$ para pemimpin tingkat menengah pada Yayasan Pelayanan Desa mengerjakan tugas-tugasnya.

\section{Daftar Pustaka}

Carson Pue, Mentoring Leaders,

Penerbit ANDI, Yogyakarta, 2010

Colquit, LePine \& Wesson,

Organizational Behavior, Improving

Performance and Commitment in the

Workplace, Fourth Edition, Mc Graw-Hill

Education, New York 2015

Derek Rolinson, David Edward, and Aysen Broadfield, Oganizational Behavior and Analysis : An Integrated Approach, New York Published 1998

George Barna, Leaders on

Leadership (Pemimpin tentang

Kepemimpinan Gandum Mas Malang 2009

Henry dan Richard Blackaby, Kepemimpinan Rohani.Batam:Gospel Press, 2005

Helen Dresky, International Management Managing Across Brodersand Cultures, Pearson Prentise Hall New Jersey 2008

Ivanka Menken, Organizational Behavior and Leadership Management Essentials, ITIL IT Service Management Framework London 2009

\section{J. Salusu, Prof Dr, Pengambilan}

Keputusan Strategik Untuk Organisasi Publik dan Organisasi Nonprofit, PT

Gramedia Widiasarana Indonesia, Jakarta 1996

John M. Bryson, Strategic

Planning For Public and Nonprofit

Organizations, Fourth Edition, Jossey-

Bass A Wiley Imprint, San Fransisco 2011 
John Maxwell, The 5 Levels of

Leadership, MIC Publisihing, Surabaya, 2017

John M. Ivancevich, Robert Konopaske, Human Resource Management, McGraw-Hill New York 2013

John R. Schermerhom et. al., Organizational Behavior, John Wiley \& Sons Inc USA 2011

Kaswan, Coaching dan Mentoring. (Bandung, Alfabeta)

Ken Blanchard, Apa Itu

KepemimPinan Pelayan? Dalam Servant

Leadership In Action, BPK Gunung Mulia, Jakarta 2019

Luthans, Organizational Behavior, An Evidence-Based Approach. $12^{\text {th }}$ edition, Mc Graw-Hill Irwin, New York 2011

Oswald Sanders, Kepemimpinan

Rohani. Yayasan Kalam Hidup

Paul D. Stanley \& Robert Clinton, Mentor, Anda Perlu Mentor dan Bersedia Menjadi Mentor, Penerbit Gandum Mas, Malang 2004

Robby I. Chandra, Pemimpin dan Mentoring Dalam Organisasi, Generasi Info Media, Jakarta 2006

Richard M. Hodgetts, Fred Luthans, dan Jonathan P. Doh, Internasional Management Culture, Strategy, and Behavior, McGraw Hill New Jersy 2012

Robert Kreitner and Angelo Kinicki, Organizational Behavior, Key Concepts, Skills and Best Practices, McGraw-Hill Companies Inc New York 2008

Stephen P. Robbins \& Timothy A. Judge, Perilaku Organizational, Salemba Empat, Jakarta 2015

Stephen P. Robbins dan Mary Coulte, Management Global Edition, Person Education limited England 2012
Stephen R. Covey, The $8^{\text {th }}$ Habit, Melampaui Efektivitas, Menggapai Keagungan, Gramedia Pustaka Utama, Jakarta 2005

Tim Elmore, Mentoring, How to Invest Your Life in Others, EQUIP and Emerging Young Leaders, USA 2004

Trianto Safira. Kepemimpinan. Yogyakarta : Graha Ilmu, 2004.

Togi Simanjuntak, The art Of Mentoring, Jakarta, Metanoia Publishing 2012 